\title{
Editorial
}

\section{Psychiatric research in occupational medicine: the future of an illusion?}

During the second world war psychiatry developed to occupy an important place in military medicine. An extraordinary synthesis occurred which allowed the application of new techniques for the selection and training of troops as well as the prompt identification and treatment of men suffering from "shell shock" and battle neuroses: one result of this was that morale was reported to be higher and the psychiatric casualty rate lower than in the first world war.

It was inevitable that attempts would be made to apply the insights of clinical psychiatry, in a similar way, to the problems confronting occupational medicine. In 1943 a symposium on "Psychiatric advice in industry" was told by Aubrey Lewis, perhaps the most influential psychiatrist of his day, that his colleagues of the future would almost become fixtures in the workplace, providing vocational guidance and identifying sources of psychological disturbance, thereby increasing productivity.'

At the same time, within psychiatry, the importance of the "occupational factor" in successfully rehabilitating patients with major psychoses was recognised. Links between psychiatry and industry became close with the establishment of industrial rehabilitation units, simulating factories, within mental hospitals. ${ }^{2}$

In the immediate postwar period this optimism encouraged an immense growth in research into the psychiatric problems specific to work and occupational settings. Groups in the United King$\mathrm{dom}^{3}$ and in the United States ${ }^{4}$ examined such subjects as absenteeism and accident proneness as psychiatric problems, demonstrating how intervention could improve performance. An academic framework supported this: the Medical Research Council in the United Kingdom founded no less than three units devoted to industrial psychiatry alone. ${ }^{2}$

By the early 1970s this promise had proved false: although the reasons are obscure, Murphy in his sad review, "The decline of industrial psychiatry" described how the institutional organisation decayed as psychiatric interest moved to other areas and suspicion grew within occupational medicine. It was, as he writes, "hard ... to avoid the conclusion that relations between psychiatry and industry have deteriorated instead of improving ... a clear opportunity for primary prevention has been lost."2
Fourteen years later the situation is, if anything, bleaker: research in the area of occupational psychiatry has diminished to an intermittent trickle while clinical opportunities are rare.

The average psychiatrist receives no postgraduate training in even the rudiments of occupational medicine and generally regards employment as a rare but valuable opportunity for rehabilitation for his patients. The occupational physician, on the other hand, is more likely to receive a training in occupational psychology or ergonomics than in psychiatry and such as there is would appear to concentrate on the major psychoses which are rare in working populations.

The resulting mutual ignorance and the failure to understand the other discipline's point of view only broadens the gap produced by the very different development of the specialities.

The most important successes in postwar occupational medicine have been in the application of epidemiology to the occupational cancers: this has become the central paradigm of the specialty. ${ }^{5}$ There is a major advantage that "normal" and "pathological" have little or no overlap whereas advanced methods of recording mortality linked to occupation encourage the process. Furthermore, the evolution of toxicology has allowed the efficient laboratory testing of hypotheses derived from such epidemiological studies.

The development of effective treatments for the major psychiatric disorders has led to an explosion in research into psychiatric epidemiology. It is now apparent that overt psychiatric illness-for example, rates of presentation to psychiatrists-represents only a small fraction of the population's total "load" of psychiatric disorder. The discovery that even major psychopathology is not incompatible with leading a normal life has tended to highlight problems of classification and case definition. ${ }^{6}$

Although the details are far from resolved, it is now accepted that satisfactory psychiatric research depends on the use of validated interviews and questionnaires to detect symptoms and syndromes rather than on the use of clinical diagnoses.

In the developed world the classic diseases of occupation are disappearing or becoming rarities as working conditions improve: they are being replaced by those illnesses with few or no physical signs, those 
with symptoms such as fatigue, forgetfulness, or anxiety. The patients with such conditions present not to the psychiatrist but to the occupational physician.

The search for single aetiologies, which occurs in internal medicine, has long been abandoned in most of psychiatry since it has been judged to yield few useful results. Whereas psychiatrists may have radically differing views on the relative contributions of different agents they tend to agree that the aetiology of most mental illness is multifactorial. The best aetiological research in psychiatry is multidisciplinary and expensive.

Unfortunately, the absence of an occupational psychiatry based on such principles has meant that the "new" diseases of occupation are investigated in a manner similar to physical ailments. For example, psychometric tests measuring psychological functions are applied and their results interpreted as though they were equivalent to an erythrocyte sedimentation rate or an $\mathrm{FEV}_{1}$, or questionnaires are used to diagnose "depression."

Also, unfortunately, psychometric tests were developed to measure given functions of the psyche: a small proportion of these may be used to document cerebral dysfunction if applied correctly. It is far from clear if any value remains if these diagnostic tests are used as research tools to large numbers of workers. They certainly cannot generate a meaningful diagnosis any more than can a questionnaire. Yet the literature on, for example, the adverse effects of solvents is now occupied by such studies having forced a few psychiatric contributions out. ${ }^{7}$

It is probably unpalatable but if occupational medicine is to explore psychiatric disturbance among working populations then it is vital that some dialogue and cooperation is established with the discipline of psychiatry.

Division of Psychiatry,

R R O'FLYNN

United Medical and Dental Schools of Guy's \& St Thomas's Hospitals,

Guy's Hospital,

London Bridge, London SE1 9RT.

\section{References}

1 Lewis A. Psychiatric advice in industry. Br J Ind Med 1945;2:41-2.

2 Murphy HBM. The decline of industrial psychiatry. Psych Med 1973;3:405-10.

3 Markowe M. Occupational psychiatry: an historical journey and some recent researches. Journal of Mental Science 1953;99: 92-102.

4 McClean A. Occupational mental health: review of an emerging art. Am J Psychiatry 1966;122:961-76.

5 Landrigan PJ. Toxic exposures and psychiatric disease-lessons from the epidemiology of cancer. Acta Psychiatr Scand 1983;67 suppl 305:6-15.

6 Kendall RE. The role of diagnosis in psychiatry. Oxford: Blackwell, 1975

7 O'Flynn RR. Do organic solvents "cause" dementia? International Journal of Geriatric Psychiatry (in press).

\section{Guidance for authors}

The British Journal of Industrial Medicine publishes material that is relevant to any aspect of occupational health. Papers that deal with environmental medicine will also be considered. The journal publishes four types of communication, original papers, short reports (which may include reports of clinical material), editorials, and letters to the Editor. Review articles are normally specially commissioned, and authors should not submit such a review without prior consultation with the Editor.

All material submitted to the journal must be typewritten on one side of the paper only with double spacing and wide margins. Manuscripts must be submitted in triplicate to the Editor, BMA House, Tavistock Square, London WC1H9JR; they must conform with the recommendations given below. Manuscripts must be written in English and spelling must follow the conventions in the Chambers Twentieth Century Dictionary. Both SI units and their equivalents must be given throughout. Authors should note that clarity and brevity are virtues that are given great weight when considering a paper for publication. The Editor cannot enter into correspondence about papers that are rejected as being unsuitable for publication and his decision is final. Rejected manuscripts will not be returned to authors, instead they will be kept securely for three months and then shredded. Authors are advised, therefore, not to submit original illustrations with their manuscripts but rather good quality reproductions. The original illustrations should be forwarded to the Editor on acceptance of the manuscript.

Papers are accepted on the understanding that the work described has not appeared in whole elsewhere and that they are subject to editorial revision. Where the findings have been published elsewhere in part this must be clearly stated and the submitted manuscript should be accompanied by a copy of the publication that contains those findings. If part of the findings are contained in a manuscript that is under consideration elsewhere a copy of that manuscript should be included with that submitted to the journal. A letter giving consent to publication must be signed by all those whose name appears on the manuscript. Papers 